\title{
Assessment of interspecific interactions between the invasive red-claw crayfish (Cherax quadricarinatus) and the Mozambique tilapia (Oreochromis mossambicus)
}

\author{
S. Chivambo * (D), A. Mussagy ${ }^{b}$ (D) and A. Barkic \\ ${ }^{a}$ Golder Associados Moçambique Limitada, Millennium Park Building, Vladimir Lenine Avenue, 174, 6 floor, \\ Maputo, Mozambique \\ ${ }^{b}$ Department of Biological Science, Faculty of Science, Eduardo Mondlane University, Main Campus, 3453, \\ P.O. Box 257, Maputo, Mozambique \\ ${ }^{c}$ Department of Poultry and Aquaculture, Institute of Animal Science, Agricultural Research Organization, \\ The Volcani Center, 68 HaMaccabim Road, P.O.B 15159, 7505101, Rishon LeZion, Israel \\ *e-mail: simpliciochivambo@gmail.com; schivambo@golder.com
}

Received: December 18, 2018 - Accepted: June 25, 2019 - Distributed: November 30, 2020

(With 3 figures)

\begin{abstract}
The Australian red-claw crayfish, Cherax quadricarinatus, has been introduced for aquaculture purposes worldwide and consequently colonized natural environments, where it might cause ecosystem services losses or adversely affect native species and the local environment. This species was first found in Pequenos Libombos Reservoir in Maputo Province, Southern Mozambique in the late 2009 and is linked to reduction in tilapia fisheries. This study, conducted in 2015 under controlled conditions, aimed to assess the interspecific relationships between the Mozambique tilapia (Oreochromis mossambicus) and the alien crayfish. For both species, no significant differences in growth and survival rates were found between animals reared in the presence versus the absence of heterospecifics, indicating no direct deleterious interspecific effects. Behavioural observations revealed that fish and crayfish competed for shelter and food. Both species reduced the foraging in the presence of heterospecifics during feeding period, in the daytime. Crayfish seemed to have an advantage in competition for shelter, suggesting that they may interfere with tilapia sheltering activity and make tilapia vulnerable to predators in natural habitats.
\end{abstract}

Keywords: competition, species introduction, non-native species, Pequenos Libombos Reservoir.

\section{Avaliação das interações interespecíficas entre o lagostim invasivo de garra vermelha (Cherax quadricarinatus) e a tilapia de Moçambique (Oreochromis mossambicus)}

\section{Resumo}

O lagostim australiano, Cherax quadricarinatus, tem sido introduzido para fins de aquicultura em todo o mundo e, consequentemente, colonizado ambientes naturais, onde pode coexistir com a biota local sem causar perdas nos serviços dos ecossistemas ou afetar negativamente as espécies nativas e o meio ambiente local. Esta espécie foi encontrada pela primeira vez na Albufeira dos Pequenos Libombos, na Província de Maputo, sul de Moçambique, no final de 2009 e foi relacionada à redução da pesca de tilápias registrada na mesma localidade. Este estudo, conduzido em 2015 sob condições controladas, teve como objetivo avaliar as relações interespecíficas entre a tilápia de Moçambique (Oreochromis mossambicus) e o lagostim invasor (C. quadricarinatus). Para ambas espécies, não foram encontradas diferenças significativas nas taxas de crescimento e sobrevivência entre animais criados na presença versus ausência de heteroespecíficos, indicando ausência de efeitos deletérios interespecíficos diretos. Observações comportamentais revelaram que peixes e lagostins competiam por abrigo e comida. Ambas espécies reduziram o forrageamento na presença de heteroespecíficos durante o período de alimentação, no período diurno. O lagostim parece ter uma vantagem na competição por abrigos, sugerindo que, em habitats naturais eles podem provocar o deslocamento de tilápias de seus abrigos, e deste modo tornar as tilápias vulneráveis aos predadores.

Palavras-chave: competição, espécies introduzidas, espécies não nativas, Albufeira dos Pequenos Libombos. 


\section{Introduction}

Freshwater ecosystems are often subject to human-mediated introduction of invasive species. Many species of decapod crustaceans and fish have been widely translocated beyond their natural range and introduced into new environments for multiple purposes, such as farming, pest control or adornment as pets (Holdich et al., 2009; Lodge et al., 2000, 2012). For example, Tilapia species have been moved from Africa throughout the tropics (Reynolds, 2011) while crayfish have been moved from North America to Europe, Asia and Africa (Holdich et al., 2009; Reynolds, 2011) and from Australia to Africa, Europe and South America (De Moor, 2002; Harlioğlu and Harlioğlu, 2006; Leitão, 2009). As a result, many of these species have been accidentally or deliberately introduced into natural freshwater ecosystems such as lakes, reservoirs and river basins, where self-sustaining feral populations became established and widespread (Ahyong and Yeo, 2007; Doupé et al., 2004; Goren and Galil, 2005; Leland et al., 2012).

Introduction of alien species such as crayfish and fish into natural ecosystems may cause losses to ecosystem services by decreasing the abundance of wild native species through competition and predation, increasing the cost of harvesting (Lodge et al., 2012), altering the ecosystem food-web and modifying habitats (Gherardi and Holdich, 1999; Kumar, 2000; Lodge et al., 2000; Reynolds, 2011). Hence, biological invasion is one of the most deleterious pressures on freshwater ecosystems in the world (Rahel and Olden, 2008).

In natural ecosystems, native crayfish and fish may co-exist with the local biota within the normal ecosystem dynamics patterns of an undisturbed habitat (Reynolds, 2011), in which an equilibrated competition for food and shelter, and mutual predation could occur (Carpenter, 2005; Griffiths et al., 2004). However, in non-natural situations involving introduction of alien crayfish, the ecosystem may not support fish populations due to predation or competition between both species (Reynolds, 2011).

The presence of introduced species can influence the spatial distribution and behaviour of the native species, alter shelter and microhabitats use, restrict activity and thereby interfere with foraging behaviour, which may affect the growth and survival rates of the native species (Lodge et al., 2012; Milinski and Heller, 1978; Rahel and Stein, 1988; Reynolds, 2011; Twardochleb et al., 2013). For example, Carpenter (2005) demonstrated experimentally that an introduced crayfish negatively affect fish growth by competing for food. Crayfish can also prey on fish eggs, feed on dead fish and chase fish fry, influencing the spatial distribution and density of fish (Minckley and Craddock, 1961; Rubin and Svensson, 1993; Savino and Miller, 1991).

Although invasive crayfishes are known to impact negatively on native fish, predatory native fishes may also negatively affect introduced crayfish, by controlling crayfish density, distribution, growth and mortality rates (Blake and Hart, 1995; Degerman et al., 2007; Englund,
1999; Peay et al., 2009; Söderbäck, 1994). Predatory fish may also affect crayfish abundance and behaviour (Englund and Krupa, 2000; Nyström, 2002).

A crayfish species was observed, for the first time, in the Pequenos Libombos reservoir in Maputo Province, southern Mozambique during late 2009 and early 2010 (A. Mussagy, unpublished data). Our first study in this reservoir, in 2011, provided a baseline data of the crayfish, which included the taxonomic identification, abundance and diet (Chivambo, 2011). An alien crayfish species was identified as the Australian red-claw crayfish (Cherax quadricarinatus Von Martens, 1868) (Chivambo, 2011), a robust and fast-growing species, which is able to grow in a wide variety of environments (Jones, 1990). The red-claw crayfish probably reached the reservoir from an aquaculture farm next to the Sand River Dam in Swaziland, through Umbeluzi River, which has direct contact with Sand River, probably during flood events (A. Mussagy, unpublished data).

Our study was motivated by the fact that the first appearance of the crayfish on the fishing nets of the fishermen as by-catch, coincided with the decline of tilapia catch per unit effort; tilapia predation by the alien crayfish was suggested as a possible cause. To test this hypothesis, specimens of the alien crayfish were subject to gut content analyses (Chivambo, 2011). The gut content analysis revealed a variety of food items, such as sediments, C. quadricarinatus exoskeleton pieces, fish scales (including tilapia scales) and other non-identified items such as animal and plant pieces and detritus, indicating that the red-claw crayfish is a generalist omnivore. Although more than $10 \%$ of the alien crayfish diet was composed of tilapia fish, the gut content analysis was not conclusive to support whether alien crayfish actively prey on tilapia or if they feed on fish carcasses which are deposited on the bottom of the reservoir (Chivambo, 2011), thus requiring further investigation. Mozambique tilapia (Oreochromis mossambicus Peters, 1852) is also known to be an omnivore species feeding on algae, plant, detritus, small invertebrates and fish (FERAL, 2013), suggesting a possible diet overlap between both species, which can interfere with tilapia foraging, resulting in competition and consequently impacting growth and survival rates. So far, interactions of tilapia and red-claw crayfish have been studied mainly in the context of aquaculture (Barki et al., 2001; Brummett and Alon, 1994; Karplus et al., 2001; Rouse and Kahn, 1998). Thus, the direct impact of this alien crayfish species on tilapia populations (e.g., growth and survival) and the type of competitive interaction between the species are not fully understood. In addition, both species seem to tolerate a wide range of ecological conditions, from fast flowing rivers and coastal streams to slower moving upper reaches of rivers, lakes and lagoons (FERAL, 2013; Russell et al., 2012). Thus, there might be a potential habitat overlap, which can create conditions for space and shelter disputes. However, it is unknown whether space or shelter is a limiting factor at the Pequenos Libombos, since such studies have never been conducted. 
This study aims at expanding our scope of inquiry by assessing under laboratory conditions the interspecific interaction between Mozambique tilapia and the invasive red-claw crayfish in order to evaluate whether the crayfish may prey actively on tilapia or affect its growth, survival and behaviour.

\section{Material and Methods}

\subsection{Experimental animals and holding aquaria}

Red-claw crayfish (C. quadricarinatus) used in the trial were obtained from fisherman at Pequenos Libombos Reservoir fishery centre located at Boane district, approximately $45 \mathrm{~km}$ southwest of the city of Maputo, Mozambique. Mixed size groups of selected individuals (18.38-46.26 g) were placed in aquaria provided with shelters and aeration for approximately four weeks for acclimatization before commencing the experiment. During this period, crayfish were daily fed with dry prawns. Approximately $2 / 3$ of the holding aquaria water was replaced with tap water once a week.

Mozambique tilapia fish were sourced from a commercial fish farm in Vilankulos, Inhambane Province. All selected individuals (6-42 g) were placed in holding aquaria provided with shelters and constant aeration for one week of acclimatization before commencing the experiment. During acclimation, the individuals were daily fed with commercial fish pellets.

\subsection{Experimental set-up}

The experiment was conducted at the Ecology Research Laboratories, Department of Biological Science, Eduardo Mondlane University Campus, Maputo, Mozambique from March to July 2015. The laboratory was not temperature controlled and no artificial light was used to manipulate the day/night cycle. The experiment coincided with the dry and cold season, when the temperature range between $22-26{ }^{\circ} \mathrm{C}$ and the day/night cycle is $11 / 13 \mathrm{~h}$.

The experimental set-up consisted of three parallel stands housing nine experimental aquaria $(91 \times 38 \times 39.5 \mathrm{~cm})$. Three polyvinyl chloride (PVC) pipes with $110 \mathrm{~mm}$ diameter and approximately $15 \mathrm{~cm}$ length were placed into each aquarium as shelters. With the exception of the front side, all sides and tops of the aquaria were visually isolated with black plastic sheets to minimize external disturbance and to eliminate the possibility of interactions between aquaria. ALED headlight (Headlamp ${ }^{\mathrm{TM}}$ ) was used to observe the individuals during the night.

Each aquarium was filled with approximately 80 litres of tap and provided with constant aeration. An internal power filter (Aqua f300) was used for circulation and filtration of water. To avoid excess of ammonia, a third part of the water in each aquarium was replaced twice a week. Measurements of temperature, $\mathrm{pH}$, conductivity, and total dissolved solids were performed using a handled Eutech instruments (cyberscan PC 300); Ammonia was measured using Hach test kit model FF-2 and dissolved oxygen was measured using handled oxygen probe (Extech D.O 600).
Water quality parameters were monitored on a weekly basis. The mean values of all parameters (Temp $25.9{ }^{\circ} \mathrm{C}$; pH 8.3; $\mathrm{O}_{2} 8.3 \mathrm{mg} / \mathrm{L}$; E.C $655.5 \mu \mathrm{S} / \mathrm{cm}$; TDS 330.4; $\left.\mathrm{NH}_{3} 0.06 \mathrm{mg} / \mathrm{L}\right)$ were within acceptable limits for tilapia and crayfish culture (El-Sayed, 2006; Masser and Rouse, 1997), indicating that the water quality was not a limiting factor in this study.

\subsection{Experimental design and procedure}

Fish and crayfish were sorted, weighed and stocked in glass aquaria in the following groups, each in three replications: 1) mixed groups composed of three individuals of crayfish and six individuals of Mozambique tilapia in a species ratio of 1 crayfish: 2 tilapia, 2) all-crayfish groups composed of three individuals and 3) all-tilapia groups composed of six individuals. The mean body masses of fish and crayfish were, respectively, 20.56 $\pm 3.6 \mathrm{~g}$ and $46.8 \pm 2.78 \mathrm{~g}$ in the mixed groups, and $18.38 \pm 1.04 \mathrm{~g}$ and $46.26 \pm 12.38 \mathrm{~g}$ in the single species groups. The proportion density of 1:2 between crayfish and fish was selected since it reflects the natural density at Pequenos Libombos when the first gross assessment was conducted (Chivambo, 2011). Mozambique tilapia and red-claw crayfish are characterized by indeterminate growth and can grow over $400 \mathrm{~g}$ (Masser and Rouse, 1997; FWS, 2011); in order to test the impact of the interspecific interaction on growth, individuals in a growth phase were selected for the experiment.

The experiment was conducted for a period of 12 weeks. During the experiment, fish and crayfish were fed twice a day, six days a week, with commercial feed pellets at a daily ration of $2 \%$ of their biomass. This amount of food is less than sufficient for fish under controlled conditions where there is no other food resources. Similar daily food rations (and even higher) were previously used in studies on tilapia $\times$ crayfish food competition and growth in communal culture (Barki and Karplus, 2016; Barki et al., 2001; Karplus et al., 2001). Thus, the food was most likely a limiting resource in our experiment. Indeed, we frequently observed the animals rushing towards the food when it was provided (exploitation competition). Crayfish were fed with sinking pellets since they are bottom-feeding organisms, while fish were fed with both sinking and floating pallets since they feed from both water column and substrate. The amount of pellets provided was weekly adjusted to the body mass after counting and weighing the individuals.

\subsection{Data collection and processing}

\subsubsection{Growth and survival rate}

Growth was calculated in terms of specific growth weight $(S G R)$ by the following Formula 1:

$$
S G R\left(\% d a y^{-1}\right)=100(\ln W f-\ln W i) / t
$$

where: Wi and Wf are the initial and final weights, respectively, and $\mathrm{t}$ is the time in days ( 84 days).

Survival rate $(\mathrm{Sr})$ was calculated as the percentage of individuals that survived by the following Formula 2: 


$$
\operatorname{Sr}(\%)=(N f / N i) \cdot 100
$$

where: Ni and Nf are the initial and final numbers of individuals alive, respectively.

\subsubsection{Behaviour}

Behavioural observations were carried out in all aquaria every week, by a single observer, in four separate occasions: non-feeding and feeding period during both the day and night. Feeding period corresponds to the time of day in which food was administered into the aquarium. Daytime observations were carried out between 06:00-08:00 and 12:00-14:00. Night-time observations were carried out between 18:00-20:00 and 20:00-22:00. At each observation period, a focal animal sampling method (Martin and Bateson, 1995) was used, in which the behaviour of a specific individual within the group was observed at 30 seconds intervals during 5 minutes. To facilitate identification of focal individuals, crayfish individuals were marked with coloured nail varnish while fish identification was based on individual specific features (e.g., body marks and size) previously recorded.

The following behavioural parameters were recorded in this study: 1) shelter use - the proportion of observations (of 10 observation intervals during $5 \mathrm{~min}$ ) in which an animal was observed inside a shelter; 2) foraging - the proportion of observations in which an animal was observed feeding; 3) aggressiveness - the proportion of observations in which an animal was observed performing aggressive actions (fighting or chasing) towards conspecifics (intraspecific aggression) and heterospecifics (interspecific aggression).

\subsection{Statistical analysis}

The effect of the absence versus presence of heterospecifics on specific growth rate (SGR) of tilapia individuals $(\mathrm{n}=18)$ and crayfish individuals $(n=9)$ was analysed using a mixed model analysis of variance (ANOVA) (type III SS) with the aquarium as random effect. The non-parametric Mann-Whitney test was used to compare survival rates of fish and crayfish in the presence versus absence of heterospecifics $(n=3)$.

For the behaviour analysis, mean values per aquarium of the tested behavioural parameters were used, since occasional uncertainty in individuals' identification (due to difficulty in distinguishing between fish individuals with similar patterns, mainly during night observations) did not enable attributing the observed behaviours to specific individuals. Therefore, the experimental unit was the aquarium $(n=3)$ and three-way ANOVA was used to test for main and interaction effects on the behavioural parameters of the following independent variables: heterospecific presence/absence, feeding/non-feeding and daytime/night-time. Since the objective of this study was interspecific effects between fish and crayfish, we mainly focused on the heterospecific-presence factor and its interaction effects with the other factors. The statistical analyses were performed using SPSS ${ }^{\mathrm{TM}}$ version 20 at a significance level of $\alpha=0.05$.

\section{Results}

\subsection{Growth and survival}

For both crayfish and tilapia, there was no significant difference in SGR between individuals reared in the absence versus presence of heterospecifics $\left(\mathrm{F}_{1,4}=1.78\right.$, $\mathrm{P}=0.25$ and $\mathrm{F}_{1,4}=1.10, \mathrm{P}=0.35$, respectively). Likewise, no significant difference in survival rate was found between crayfish or tilapia reared in the absence versus presence of heterospecifics $(\mathrm{Z}=0.0, \mathrm{P}=1$ and $\mathrm{Z}=0.7$, $\mathrm{P}=0.48$, respectively) (Table 1 ).

\subsection{Behaviour}

\subsubsection{Shelter use}

In general, crayfish were observed in shelter significantly more frequently during the day than during the night $\left(\mathrm{F}_{1,1630}=304.9, \mathrm{P}<0.001\right)$ (Figure 1a). There were no significant main effects on crayfish shelter use of the heterospecific presence $\left(\mathrm{F}_{1,1630}=0.85, \mathrm{p}=0.36\right)$ and the feeding $\left(\mathrm{F}_{1,1630}=1.10, \mathrm{p}=0.29\right)$ factors. However, a significant interaction between heterospecific presence and feeding $\left(\mathrm{F}_{1,1630}=4.2, \mathrm{p}=0.041\right)$ revealed a feeding-dependent effect of tilapia presence on crayfish shelter use; in the daytime, the reduction in crayfish shelter occupation during feeding compared to non-feeding was much higher in the presence of fish than in their absence (Figure 1a). No such effect was evident in the night-time, when the fish are less active (Figure 1a).
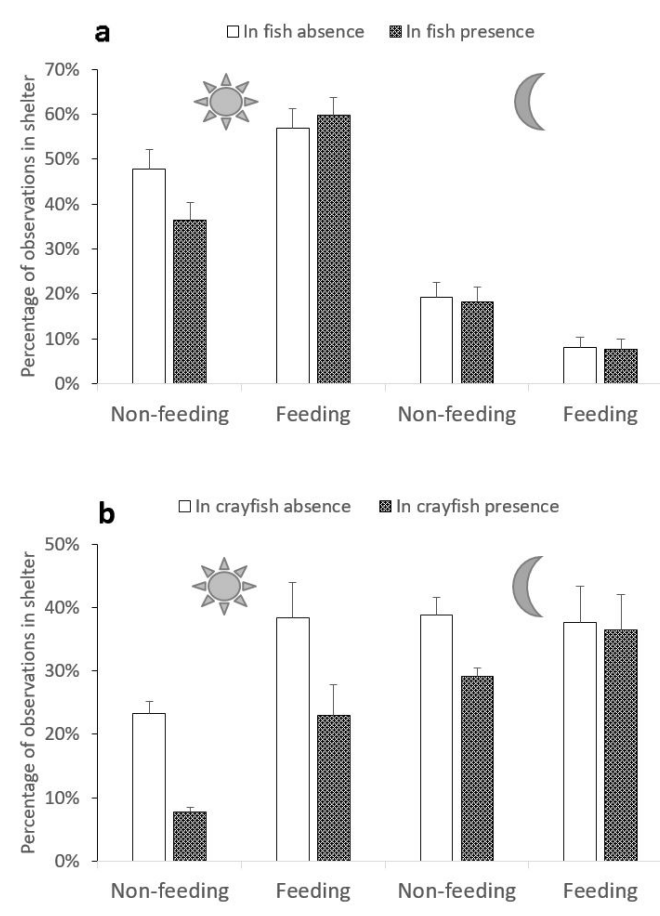

Figure 1. Percentage of observations in which crayfish (a) and tilapia (b) were observed in shelter, in the absence vs. presence of heterospecifics, during feeding and non-feeding periods, in both the daytime and night-time (depicted by the sun and moon, respectively). Error bars represent standard error. 


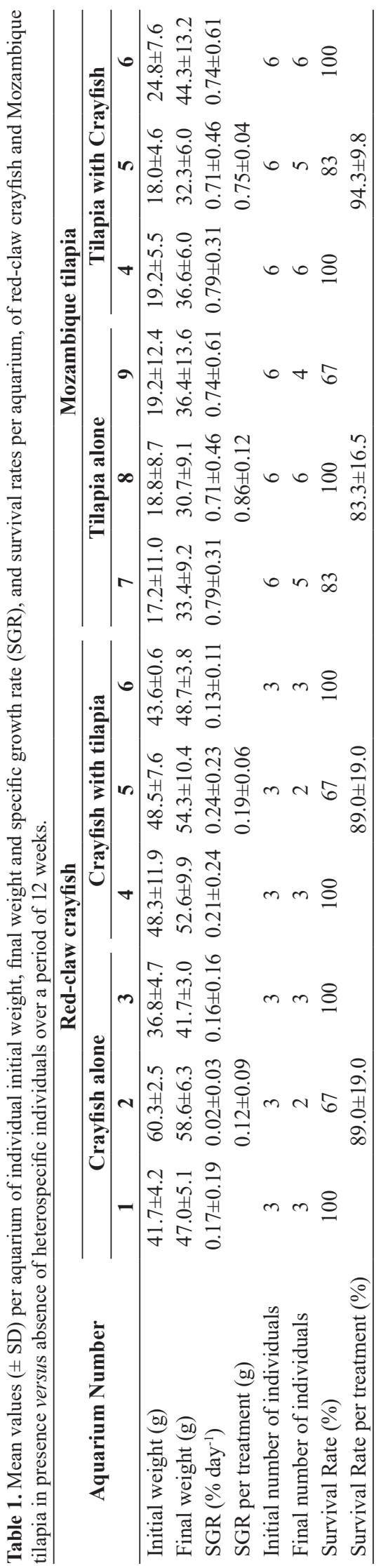


In contrast to crayfish, fish were observed in shelter significantly more frequently during the night than during the day $\left(\mathrm{F}_{1,1642}=29.8, \mathrm{P}<0.001\right)$ (Figure $1 \mathrm{~b}$ ). A significant interaction between the heterospecific presence and the day/night factors $\left(\mathrm{F}_{1,1642}=3.85, \mathrm{p}=0.02\right)$ revealed that the presence of crayfish significantly decreased tilapia shelter occupation during the day, when crayfish tend to be in shelter (Figure 1b).
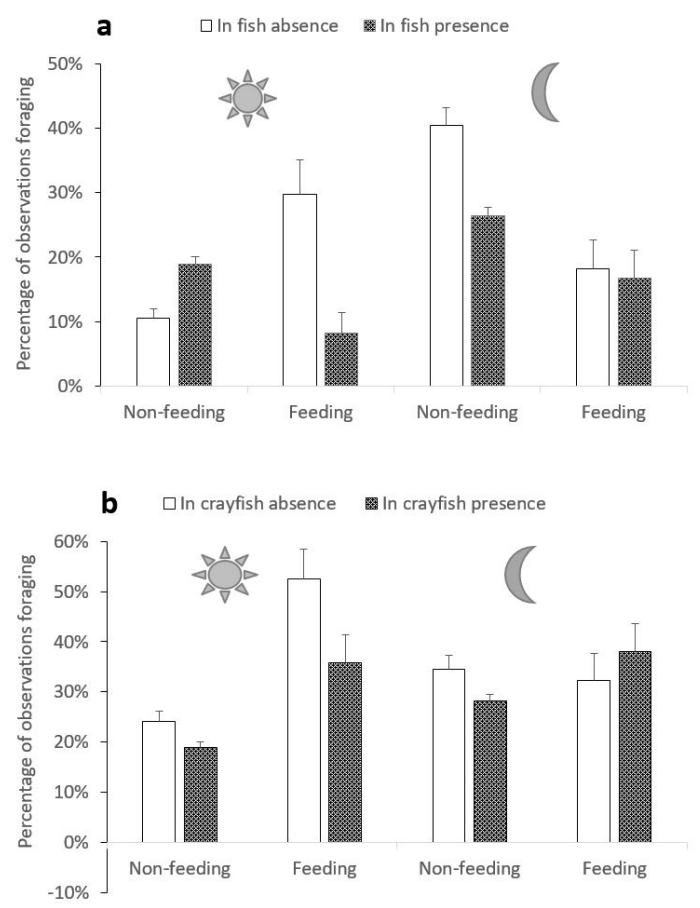

Figure 2. Percentage of observations in which crayfish (a) and tilapia (b) were observed foraging, in the absence vs. presence of heterospecifics, during feeding and non-feeding periods, in both the daytime and night-time (depicted by the sun and moon, respectively). Error bars represent standard error.



Figure 3. Percentage of observations in which crayfish addressed aggressive actions towards tilapia during feeding and non-feeding periods, in the daytime and night-time. Error bars represent standard error.

\subsubsection{Foraging behaviour}

In general, crayfish were observed foraging more frequently during the night than during the day $\left(\mathrm{F}_{1,1630}=17.91\right.$, $\mathrm{P}<0.001$ ) (Figure 2a). Significant heterospecific presence $x$ feeding interaction $\left(\mathrm{F}_{1,1630}=4.53, \mathrm{P}=0.033\right)$ and second-order interaction among the three tested factors $\left(\mathrm{F}_{1,1630}=27.39\right.$, $\mathrm{P}<0.001$ ) revealed a reduction in crayfish foraging behaviour in the presence of tilapia mainly in the feeding period during the day (when tilapia are active) (Figure 2a).

There were significant main effects on tilapia foraging behaviour of heterospecific presence $\left(\mathrm{F}_{1,1642}=5.84, \mathrm{P}=0.016\right)$ and feeding $\left(\mathrm{F}_{1,1642}=31.85, \mathrm{P}<0.001\right)$. A significant heterospecific $\times$ day/night interaction $\left(\mathrm{F}_{1,1642}=5.17\right.$, $\mathrm{P}=0.023$ ) revealed that crayfish presence reduced tilapia foraging mainly during the day (Figure 2b). A significant second-order interaction among the three tested factors $\left(\mathrm{F}_{1,1642}=6.18, \mathrm{P}=0.013\right)$ revealed that the presence of crayfish affected tilapia foraging behaviour in the daytime during both feeding and non-feeding periods, while at night-time it reduced tilapia foraging only during non-feeding periods (Figure 2b).

\subsubsection{Agreessivness}

\subsubsection{Intraspecific interactions}

Crayfish aggressive actions towards conspecifics were not significantly affected by any of the tested factors and no significant interaction effects between the tested factors were found $\left(\mathrm{F}_{1,1630}=0.056 ; \mathrm{P}>0.05\right)$.

Tilapia aggressive actions towards conspecifics were only affected by the day/night factor $\left(\mathrm{F}_{1,1642}=177.9, \mathrm{P}<0.001\right)$, performed exclusively during the day (Figure 3 ).

\subsubsection{Interspecific interactions}

Almost no aggressive actions (only 4 occurrences) of tilapia towards crayfish were documented at any experimental period. Crayfish aggressive actions towards tilapia were observed only during the day $\left(\mathrm{F}_{1,1634}=29.25\right.$, $\mathrm{P}<0.001)$. There was no significant effect of the feeding factor or interaction effect between the two tested factors $(\mathrm{P}>0.05)$ (Figure 3).

\section{Discussion}

By means of a controlled laboratory study, we attempted to assess the direct effects that invasive crayfish, established at Pequenos Libombos Reservoir, might have on native Mozambique tilapia populations.

Growth and survival rates of Mozambique tilapia were not affected by the presence of crayfish during the study period. That red-claw crayfish does not adversely affect tilapia growth performance was also demonstrated for red hybrid tilapia under laboratory conditions (Barki et al., 2001) and in communal-culture tanks (Karplus et al., 2001). In these previous studies, the fish grew better in the presence of crayfish than in monoculture, possibly by consuming some of the feed ration intended for crayfish. Similar to tilapia, the growth of crayfish in the current study was also not adversely affected by the presence of 
heterospecifics. In contrast, Barki et al. (2001) demonstrated a negative effect of tilapia on red-claw crayfish; however, the magnitude of the negative effect depended on the size of fish relative to crayfish. Thus, the lack of effect on crayfish growth in our experiment is probably related to the relatively small size of the fish or to the different species tested. Previous experiments conducted in earthen ponds, i.e. under conditions that are more similar to a natural environment than the laboratory, showed ambiguous results concerning the mutual effect of tilapia and crayfish; Brummett and Alon (1994) showed that red-claw crayfish can negatively affect Nile tilapia (Oreochromis niloticus, Linnaeus, 1758) growth and survival while Rouse and Kahn (1998) demonstrated that crayfish had a relatively low growth when co-cultured with Nile tilapia, which was associated to the low aggressiveness of red-claw crayfish, which render them weaker competitors. However, these results should not necessarily have the same trend in natural conditions, where these omnivorous species can feed at different trophic levels. The behavioural results revealed a somewhat complex picture owing to the varying contexts in which observations were performed, in terms of prevalence of food competition (feeding versus non-feeding periods) and the differential activity of tilapia and crayfish during day and night. As a measure of predator avoidance, crayfish may reduce movement and increase the time spent in shelter in the presence of predators, which in turn may disrupt the foraging activity and impact growth (Apperberg et al., 1993; Blake and Hart, 1993; Rahel and Stein, 1988; Stein and Magnuson, 1976). Although not tested in the present experiment, the interactions under study may have been mediated also by chemical cues released by heterospecifics. For both tilapia and crayfish, heterospecific chemical cues can induce alterations in shelter use, foraging activity, aggressiveness, and ultimately affect growth and survival (Nyström and Åbjörnsson, 2000; Height and Whisson, 2006; Turner et al., 2000). A noteworthy finding in our study is that most of the interspecific behavioural effects were evident during the daytime, namely, when the diurnal fish are active and the nocturnal crayfish are less active.

The effect of tilapia on crayfish shelter occupation in the daytime seemed to depend on feeding. When we compared crayfish shelter occupation during feeding to that during non-feeding, we found a much higher increase in the presence of fish (from $36 \%$ to $60 \%$ ) than in the absence of fish (from $48 \%$ to $55 \%$ ). This result indicated an increased tendency of crayfish to stay inside the shelters in daytime during the feeding period, when the fish are competing for food, suggesting an association between food competition and the intimidating effect of fish on crayfish. Conversely, shelter use of tilapia decreased in the presence of crayfish mainly during the day when crayfish tend to be in shelter, irrespective of food competition (i.e. during both feeding and non-feeding periods); at night, when crayfish became active and left shelters, tilapia shelter use increased. A possible effect of crayfish on fish shelter use have been mainly reported for benthic fish (Guan and Wiles, 1997; Rahel and Stein, 1988). These results are somewhat different from those obtained by Griffiths et al. (2004) showing that signal crayfish (Pacifastacus leniusculus, Dana, 1852) shelter use was independent of the presence or absence of Atlantic salmon (Salmo salar, Linnaeus, 1758) while fish shelter use decreased in the presence of crayfish. Based on such observations, Griffiths et al. (2004) suggested that invasion of fish habitat by large numbers of crayfish could result in interference with sheltering of fish species and the degree of that interference will be a function of the overall availability of shelters and population densities relative to the carrying capacity of the habitat.

Concurrently with the effects on shelter use, the foraging behaviour of both tilapia and crayfish was affected by the presence of heterospecifics; this result was only evident during feeding periods in the day-time when tilapia fish actively compete for food. The effect of tilapia on crayfish foraging is in line with their effect on crayfish shelter use, indicating the importance of the food-competition context for the intimidating effect of tilapia on crayfish. On the other hand, the reduction in tilapia foraging activity in the presence of crayfish occurred during both feeding and non-feeding periods, suggesting a different context for the effect of crayfish on fish. Although this study was not focused on the effects of fish size relative to crayfish, it is evident from the results that tilapia in general tend to reduce foraging in the presence of red-claw crayfish. A detailed analysis of the foraging behaviour of red hybrid tilapia in the presence of red-claw crayfish (Barki and Karplus, 2016) revealed reduction in the time spent by small, but not by large, tilapia at a food patch on the bottom in the presence of crayfish. Apparently, small fish changed their foraging tactic from staying at the food patch when crayfish were absent to snatching food during short visits when crayfish competitors were present at the food patch. This behavioural plasticity may have enabled the small fish to consume enough food, and thus it may explain why no reduction in growth is evident in the relatively small fish used in this study.

Aggression may serve as a means for predation or for predator deterrence, as well as for interference competition for resources, which in our study were shelter and food. Only crayfish exhibited interspecific aggressive actions, which were performed almost exclusively during the day, when tilapia are active. The aggressive actions performed by crayfish included the rising of chelipeds, strike position and movements toward tilapias. These antagonist responses are typically used for predator deterrence (Hazlett, 1994; Stein and Magnuson, 1976). However, tilapia are not predatory fishes and they almost never addressed aggressive actions towards crayfish. This may imply that tilapia are primarily considered by crayfish as competitors. Since aggression was evident during both the feeding period and the non-feeding period, it seems that interspecific aggression served crayfish mainly in the context of shelter protection or as an expression of territorial behavior. Indeed, we often observed the crayfish extending their chelipeds as tilapia approached their shelters during the day. The lack of aggression of tilapia towards crayfish in aquaria has 
been previously reported for $O$. mossambicus tilapia with the red swamp crayfish Procambarus clarkii, Girard, 1852 (Martino and Wilson, 1986) and for C. quadricarinatus crayfish with red hybrid tilapia (Barki and Karplus, 2016). As different from the current study, Barki and Karplus (2016) demonstrated an indirect effect of tilapia, in which the frequency of crayfish intraspecific aggressive actions was reduced in the presence of relatively large tilapia.

Taken together, the aforementioned findings suggest that tilapia may have an advantage in competition for food whereas crayfish may have an advantage in competition for shelters on the bottom. Tilapia fish do not use aggression in competition for food, but take advantage of their mobility and rapidness to gain priority of access to food over crayfish. This mobility cannot confer a significant advantage in shelter competition. In addition, interspecific competitive relationships and the magnitude of behavioural effects may vary with the relative size of tilapia and crayfish and between day and night.

This study, conducted under controlled and confined laboratory conditions, could shed light on possible effects through direct interactions of the invasive red-claw crayfish on native Mozambique tilapia in the natural environment. However, invaders can reduce the abundance of native species indirectly, through other mechanisms (Dorn and Mittelbach, 1999; Reynolds, 2011). The present study shows that fish and crayfish may compete for shelter and food. The advantage of crayfish in competition for shelter may interfere with tilapia sheltering activity in the natural habitat and make tilapia vulnerable to other predators, as reported for other fish and crayfish interactions (Rahel and Stein, 1988). However, this could be a size dependent effect (Barki et al., 2001). We found no direct evidence for prey-predator relationships between tilapia and crayfish, and despite the fact that tilapia seemed to interfere with crayfish foraging behaviour, crayfish may maintain sustainable populations by utilizing food resources for which tilapia do not compete or by taking advantage of their nocturnal nature for gaining access to common food resources when the fish are less active (Barki et al., 2001). In addition, crayfish might adversely affect tilapia at different life history stages than in our study. For example, crayfish may disrupt tilapia reproduction by interfering with construction of spawning pits on the substrate by males, mainly during night foraging, or they may exclude young tilapia from vegetated areas where they find refuge. Crayfish are also known to be efficient predators of eggs and larval fishes (Dorn and Mittelbach, 2004; Karjalainen et al., 2015), but in the particular case of tilapia this form of interaction is unlikely to occur because tilapia are mouth-brooders. On the other hand, crayfish might also have positive indirect effects on fish, e.g., by reducing native parasites of fish through consumption of their hosts (Pulkkinen et al., 2013). Thus, for a conservation and management of aquatic ecosystems these aspects need to be further studied in more detail in natural habitats or under mesocosm conditions that closely resemble natural conditions.

\section{Acknowledgements}

The authors acknowledge the grant provided to SC by Eduardo Mondlane University and the funding provided by Golder Associates Africa, which enabled SC to run the experiment. We thank Mr. Chris Schnell and Simião Balane for assistance with sourcing of tilapia, the anonymous fishermen at Pequenos Libombos Reservoir for the sourcing of the crayfish specimens and Mr. Ivan Nerantzoulis for assisting in setting up the experiment. We also thank the managers of the Pequemos Libombos Reservoir under the Directorate of water affairs in Mozambique who informed the authors of the first appearance of crayfish in this reservoir.

\section{References}

AHYONG, S.T. and YEO, D.C., 2007. Feral populations of the Australian Red-Claw crayfish (Cherax quadricarinatus von Martens) in water supply catchments of Singapore. Biological Invasions, vol. 9, no. 8, pp. 943-946. http://dx.doi.org/10.1007/ s10530-007-9094-0.

APPERBERG, M., SÖDERBÃCK, B. and OLDERSTRÖM, T., 1993. Predator determination and perception of predation risk in crayfish Astacus L. Nordic Journal of Freshwater Research, vol. 68 , pp. 55-62.

BARKI, A. and KARPLUS, I., 2016. The behavioural mechanism of competition for food between tilapia (Oreochromis hybrid) and crayfish (Cherax quadricarinatus). Aquaculture, vol. 450, pp. 162-167. http://dx.doi.org/10.1016/j.aquaculture.2015.07.031.

BARKI, A., GUR, N. and KARPLUS, I., 2001. Management of interspecific food competition in fish-crayfish communal culture: the effects of the spatial and temporal separation of feed. Aquaculture, vol. 201, no. 3-4, pp. 343-354. http://dx.doi. org/10.1016/S0044-8486(01)00605-6.

BLAKE, M.A. and HART, P.J.B., 1993. The behavioural responses of juvenile signal crayfish, Pacifastacus lenisculus to stimuli from perch and eels. Journal of Freshwater Biology, vol. 29, no. 1, pp. 89-97. http://dx.doi.org/10.1111/j.1365-2427.1993.tb00747.x.

BLAKE, M.A. and HART, P.J.B., 1995. The vulnerability of juvenile signal crayfish to perch and eel predation. Freshwater Biology, vol. 33, no. 2, pp. 233-244. http://dx.doi.org/10.1111/j.1365-2427.1995. tb01164.x.

BRUMMETT, R.E. and ALON, N.C., 1994. Polyculture of Nile tilapia (Oreochromis niloticus) and Australian red-claw crayfish (Cherax quadricarinatus) in earthen ponds. Aquaculture, vol. 122, no. 1, pp. 47-54. http://dx.doi.org/10.1016/0044-8486(94)90332-8.

CARPENTER, J., 2005. Competition for food between an introduced crayfish and two fishes endemic to the Colorado River basin. Environmental Biology of Fishes, vol. 72, no. 3, pp. 335342. http://dx.doi.org/10.1007/s10641-004-2588-z.

CHIVAMBO, S., 2011. Avaliação da dieta do lagostim invasor na Albufeira dos Pequenos Libombos. Mozambique: Eduardo Mondlane University. Graduation thesis.

DE MOOR, I., 2002. Potential impacts of alien fresh water crayfish in South Africa. African Journal of Aquatic Science, vol. 27, no. 2, pp. 125-139. http://dx.doi.org/10.2989/1608591 4.2002 .9626584 
DEGERMAN, E., NILSSON, P.A., NYSTRÖM, P., NILSSON, E. and OLSSON, K., 2007. Are fish populations in temperate streams affected by crayfish: a field survey and prospects? Environmental Biology of Fishes, vol. 78, no. 3, pp. 231-239. http://dx.doi.org/10.1007/s10641-006-0041-1.

DORN, N.J. and MITTELBACH, G.G., 1999. More than predator and prey: a review of interactions between fish and crayfish. Vie et Milieu, vol. 49, pp. 229-237.

DORN, N.J. and MITTELBACH, G.G., 2004. Effects of a native crayfish (Orconectes virilis) on the reproductive success and nesting behaviour of sunfish (Lepomis spp.). Canadian Journal of Fisheries and Aquatic Sciences, vol. 61, no. 11, pp. 2135-2143. http://dx.doi.org/10.1139/f04-158.

DOUPÉ, R.G., MORGAN, D.L., GIL, H.S. and ROWLAND, A.J., 2004. Introduction of red-claw crayfish Cherax quadricarinatus (von Martens) to Lake Kununurra, Ord River, Western Australia: prospects for a 'yabby' in the Kimberley. Journal of the Royal Society of Western Australia, vol. 87, pp. 187-191.

EL-SAYED, A.F.M., 2006. Tilapia culture. USA: CABI Publishing. http://dx.doi.org/10.1079/9780851990149.0000.

ENGLUND, G. and KRUPA, J.J., 2000. Habitat use by crayfish in streams pools: influence of predators, depth and body size. Freshwater Biology, vol. 43, no. 1, pp. 75-83. http://dx.doi. org/10.1046/j.1365-2427.2000.00524.x.

ENGLUND, G., 1999. Effects of fish on the local abundance of crayfish in stream pools. Oikos, vol. 87, no. 1, pp. 48-56. http:// dx.doi.org/10.2307/3546995.

FERAL, 2013 [viewed 8 August 2017]. Biology and ecology of Mozambique tilapia (Oreochromis mossambicus) [online]. Australia: PestSmart. Available from: http://www.pestsmart.org. au/wp-content/uploads/2012/02/TILFS3 web.pdf

GHERARDI, F. and HOLDICH, D.M., 1999. Crayfish in Europe as non-native species: how to make the best of a bad situation. Rotterdam: A. A. Balkema, 299 p. Crustacean Issues, no. 11.

GOREN, M. and GALIL, B.S., 2005. A review of changes in the fish assemblages of Levantine inland and marine ecosystems following the introduction of non-native fishes. Ichthyology, vol. 21 , no. 4 , pp. 364-370. http://dx.doi.org/10.1111/j.14390426.2005.00674.x.

GRIFFITHS, S.W., COLLEN, P. and ARMSTRONG, J.D., 2004. Competition for shelter among overwintering signal crayfish and juvenile Atlantic salmon. Journal of Fish Biology, vol. 65, no. 2, pp. 436-447. http://dx.doi.org/10.1111/j.0022-1112.2004.00460.x.

GUAN, R.Z. and WILES, P.R., 1997. Ecological impact of introduced crayfish on benthic fishes in a British lowland river. Conservation Biology, vol. 11, no. 3, pp. 641-647. http://dx.doi. org/10.1046/j.1523-1739.1997.96073.x.

HARLIOĞLU, M.M. and HARLIOĞLU, A.G., 2006. Threat of non-native crayfish introduction into Turkey: global lesson. Reviews in Fish Biology and Fisheries, vol. 16, no. 2, pp. 171181. http://dx.doi.org/10.1007/s11160-006-9010-1.

HAZLETT, B.A., 1994. Alarm responses in the crayfish Orconectes virilis and Orconectes propinquus'. Chemistry and Ecology, vol. 20, no. 7, pp. 1525-1535. http://dx.doi.org/10.1007/BF02059878. PMid:24242649.

HEIGHT, S.G. and WHISSON, G.J., 2006. Behavioural responses of Australian freshwater crayfish (Cherax cainii and Cherax albidus) to exotic fish odour. Australian Journal of Zoology, vol. 54, no. 6, pp. 399-407. http://dx.doi.org/10.1071/ZO06011.

HOLDICH, D.M., REYNOLDS, J.D., SOUTY-GROSSET, C. and SIBLEY, P.J.., 2009. A review of the ever-increasing threat to European crayfish from non-indigenous crayfish species. Knowledge and Management of Aquatic Ecosystems, vol. 11, no. 11, pp. 394-395. http://dx.doi.org/10.1051/kmae/2009025.

JONES, C.M., 1990. The biology and aquaculture potential of the tropical freshwater crayfish Cherax quadricarinatus. Brisbane: Queensland Department of Primary Industries.

KARJALAINEN, J., RUOKONEN, T.J., MARJOMÄKI, T.J., MARTIKAINEN, A., PURSIAINEN, M., SARVALA, J., TARVAINEN, M. and VENTELÄ, A.M., 2015. Predation by signal crayfish Pacifastacus leniusculus on fish eggs and its consequences for coregonid recruitment. Journal of Fish Biology, vol. 86, no. 2, pp. 651-667. http://dx.doi.org/10.1111/jfb.12588. PMid:25605004.

KARPLUS, I., HARPAZ, S.G., HULATA, G., SEGEV, R. and BARKI, A., 2001. Culture of the Australian red-claw crayfish (Cherax quadricarinatus): IV. Crayfish incorporation into invasive tilapia products units. Israeli Journal of Aquaculture - Bamidgeh, vol. 53 , pp. 23-33.

KUMAR, A.B., 2000. Exotic fishes and freshwater fish diversity. Zoos' Print Journal, vol. 15, no. 11, pp. 363-367. http://dx.doi. org/10.11609/JoTT.ZPJ.15.11.363-7.

LEITÃO, P., 2009. Existem limites para a dispersão e colonização de novos habitats pelo lagostim Americano Procambarus clarki? Um estudo a médio prazo na Bacia do Rio Sado e elaboração de um plano de contenção. Lisboa: Universidade de Lisboa. Master Thesis.

LELAND, J.C., COUGHRAN, J. and FURSE, J.M., 2012. Further translocation of the Red-claw, Cherax quadricarinatus (Decapoda: Parastacidae), to Lake Ainsworth in north-eastern New South Wales, Australia. Crustacean Research, vol. 2012, no. 7, pp. 1-4. http://dx.doi.org/10.18353/crustacea.Special2012.7_1.

LODGE, D.M., DEINES, A., GHERARDI, F., YEO, D.C.J., ARCELLA, T., BALDRIDGE, A.K., BARNES, M.A., CHADDERTON, W.L., FEDER, J.L., GANTZ, C.A., HOWARD, G.W., JERDE, C.L., PETERS, B.W., PETERS, J.A., SARGENT, L.W., TURNER, C.R., WITTMANN, M.E. and ZENG, Y., 2012. Global introductions of crayfishes: evaluating the impact of species invasions on ecosystem services. Annual Review of Ecology Evolution and Systematics, vol. 43, no. 1, pp. 449-472. http://dx.doi.org/10.1146/annurev-ecolsys-111511-103919.

LODGE, D.M., TAYLOR, C.A., HOLDICH, D.M. and SKURDAL, J., 2000. Nonindigenous crayfishes threaten North American freshwater biodiversity: lessons from Europe. Fisheries, vol. 25, no. 8, pp. 7-20. http://dx.doi.org/10.1577/15488446(2000)025<0007:NCTNAF>2.0.CO;2.

MARTIN, P. and BATESON, P., 1995. Measuring behaviour: an introductory guide. USA: Cambridge University Press.

MARTINO, C. and WILSON, J.L., 1986. Behavioural interactions of tilapia, crawfish, and freshwater prawns in aquaculture. Aquaculture Magazine, vol. 12, pp. 36-37.

MASSER, M.P. and ROUSE, D.B., 1997. Australian red claw crayfish. Stoneville: Southern Regional Aquaculture Center, 8 p. SRAC Publication, no. 244.

MILINSKI, M. and HELLER, R., 1978. Influence of a predator on the optimal foraging behaviour of sticklebacks (Gasterosteus 
aculeatus L.). Nature, vol. 275, no. 5681, pp. 642-644. http:// dx.doi.org/10.1038/275642a0.

MINCKLEY, W.L. and CRADDOCK, J.E., 1961. Active predation of crayfish on fishes. Progressive Fish-Culturist, vol. 23, no. 3, pp. 120-123. http://dx.doi.org/10.1577/1548-8659(1961)23[120:AP OCOF]2.0.CO;2.

NYSTRÖM, P., 2002. Ecology. In: M.D. HOLDICH, ed. Biology offreshwater Crayfish. Australia: Blackwell science, pp 192-235.

NYSTRÖM, P. and ÅBJÖRNSSON, K., 2000. Effects of fish chemical cues on interactions between tadpoles and crayfish. Oikos, vol. 88, no. 1, pp. 181-190. http://dx.doi.org/10.1034/j.16000706.2000.880120.x.

PEAY, S., GUTHRIE, N., SPEES, J., NILSSON, E. and BRADLEY, P., 2009. The impact of signal crayfish (Pacifastacus leniusculus) on the recruitment of salmonid fish in a headwater stream in Yorkshire, England. Knowledge and Management of Aquatic Ecosystems, vol. 12, no. 12, pp. 394-395. http://dx.doi. org/10.1051/kmae/2010003.

PULKKINEN, K., RUOKONEN, T., MYKRÄ, M., TAMBE, G., KARJALAINEN, J. and HÄMÄLÄINEN, H., 2013. Indirect effects of invasive crayfish on native fish parasites. Ecosphere, vol. 4, no. 4, pp. 1-9. http://dx.doi.org/10.1890/ES12-00405.1.

RAHEL, F.J. and OLDEN, J.D., 2008. Assessing the effects of climate change on aquatic invasive species. Conservation Biology, vol. 22, no. 3, pp. 521-533. http://dx.doi.org/10.1111/j.15231739.2008.00950.x. PMid:18577081.

RAHEL, F.J. and STEIN, R.A., 1988. Complex predator-prey interactions and predator intimidation among crayfish, piscivorous fish and small benthic fish. Oecologia, vol. 75, no. 1, pp. 94-98. http://dx.doi.org/10.1007/BF00378819. PMid:28311839.

REYNOLDS, J.D., 2011. A review of ecological interactions between crayfish and fish, indigenous and introduced. Knowledge and Management of Aquatic Ecosystems, vol. 401, no. 401, pp. 10. http://dx.doi.org/10.1051/kmae/2011024.

ROUSE, D.B. and KAHN, B.M., 1998. Production of Australian red-claw (Cherax quadricarinatus) in polyculture with Nile tilapia Oreochromis niloticus. Journal of the World Aquaculture Society, vol. 29, no. 3, pp. 340-344. http://dx.doi. org/10.1111/j.1749-7345.1998.tb00656.x.

RUBIN, J. and SVENSSON, M., 1993. Predation by the noble crayfish, Astacus (L.) on emerging fry of sea trout, Salmo trutta (L.). Nordic Journal of Freshwater Research, vol. 68, pp. 100-104.

RUSSELL, D.J., THUESEN, P.A. and THOMSON, F.E., 2012. A review of the biology, ecology, distribution and control of Mozambique tilapia, Oreochromis mossambicus (Peters 1852) (Pisces: Cichlidae) with particular emphasis on invasive Australian populations. Reviews in Fish Biology and Fisheries, vol. 22, no. 3, pp. 533-554. http://dx.doi.org/10.1007/s11160-011-9249-z.

SAVINO, J.F. and MILLER, J.E., 1991. Crayfish (Orconectes virilis) feeding on young lake trout (Salvelinus namaycush): effect of rock size. Journal of Freshwater Ecology, vol. 6, no. 2, pp. 161-170. http://dx.doi.org/10.1080/02705060.1991.9665290.

SÖDERBÄCK, B., 1994. Interactions among juveniles of two freshwater crayfish species and a predatory fish. Oecologia, vol. 100, no. 3, pp. 229-235. http://dx.doi.org/10.1007/BF00316949. PMid:28307005

STEIN, R.A. and MAGNUSON, J.J., 1976. Behavioural response of crayfish to a fish predator. Ecology, vol. 57, no. 4, pp. 751-761. http://dx.doi.org/10.2307/1936188.

TURNER, A.M., BERNOT, R.J. and BOES, C., 2000. Chemical cues modify species interactions: the ecological consequences of predator avoidance by freshwater snails. Oikos, vol. 88, no. 1, pp. 148-158. http://dx.doi.org/10.1034/j.1600-0706.2000.880117.x.

TWARDOCHLEB, L.A., OLDEN, J.D. and LARSON, E.R., 2013. A global meta-analysis of the ecological impacts of nonnative crayfish. Freshwater Science, vol. 32, no. 4, pp. 1367-1382. http://dx.doi.org/10.1899/12-203.1.

U.S. FISH AND WILDLIFE SERVICE - FWS, 2011 [viewed 8 August 2017]. Mozambique tilapia (Oreochromis mossambicus) ecological risk screening summary [online]. Washington. Available from: https://www.fws.gov/fisheries/ans/erss/highrisk/Oreochromismossambicus-ERSS-revision-July-2015.pdf 